\title{
Erratum to: Exploring the assessment of twenty-first century professional competencies of undergraduate students in environmental studies through a business-academic partnership
}

\author{
Dave Gosselin • Sara Cooper • Ronald J. Bonnstetter • \\ Bill J. Bonnstetter
}

Published online: 28 January 2014

(C) AESS 2014

\section{Erratum to: J Environ Stud Sci (2013) 3:359-368 DOI 10.1007/s13412-013-0140-1}

After this paper was published, the authors discovered that data for 5 of the 29 students compared in Fig. 4 on page 364 had not been processed using the same algorithm as the other 24 students. When data for all 29 students are calculated using the same and appropriate algorithm, there is no statistical difference between the pre- and post-program scores as indicated in Table 2 of the original paper. Figure 4 below provides the correct data. These modified results require a change in one of the conclusions highlighted in the abstract. In addition, the results are now consistent with a longer and more comprehensive assessment of the impact of engineering curriculum and pedagogy on the development of what Pistrui et al. (2012) describes as seven discriminating skills for engineers.

Although these results are no longer statistically significant, we are confident that our approach to the development of twenty-first century competencies can be done concomitantly with the intellectual growth, the development of content knowledge, and the ability to think about systems. This study documents the use of business-based instruments, such as the TriMetrix ${ }^{\circledR}$ DNA, as part of a formative program-assessment process that can lead to major curriculum modifications and the integration of pedagogical approaches and educational practices that further promote student independence, selfdirected learning, and self-reliance.

The online version of the original article can be found at http://dx.doi.org/ 10.1007/s13412-013-0140-1.

\footnotetext{
D. Gosselin $(\bowtie) \cdot S$. Cooper

Environmental Studies Program 149 Hardin Hall,

University of Nebraska-Lincoln, Lincoln, NE 68583-0941, USA

e-mail: dgosselin2@unl.edu
}

R. J. Bonnstetter • B. J. Bonnstetter

Target Training International, Ltd., 17785 North Pacesetter Way,

Scottsdale, AZ 85255, USA 
Fig. 4 A spider diagram that compares the competencies of 29 students who entered the UNL-ES program in the Sophomore Orientation Course after the new educational approach was implemented and then went on to complete the Senior Thesis. Work force mean plotted for reference

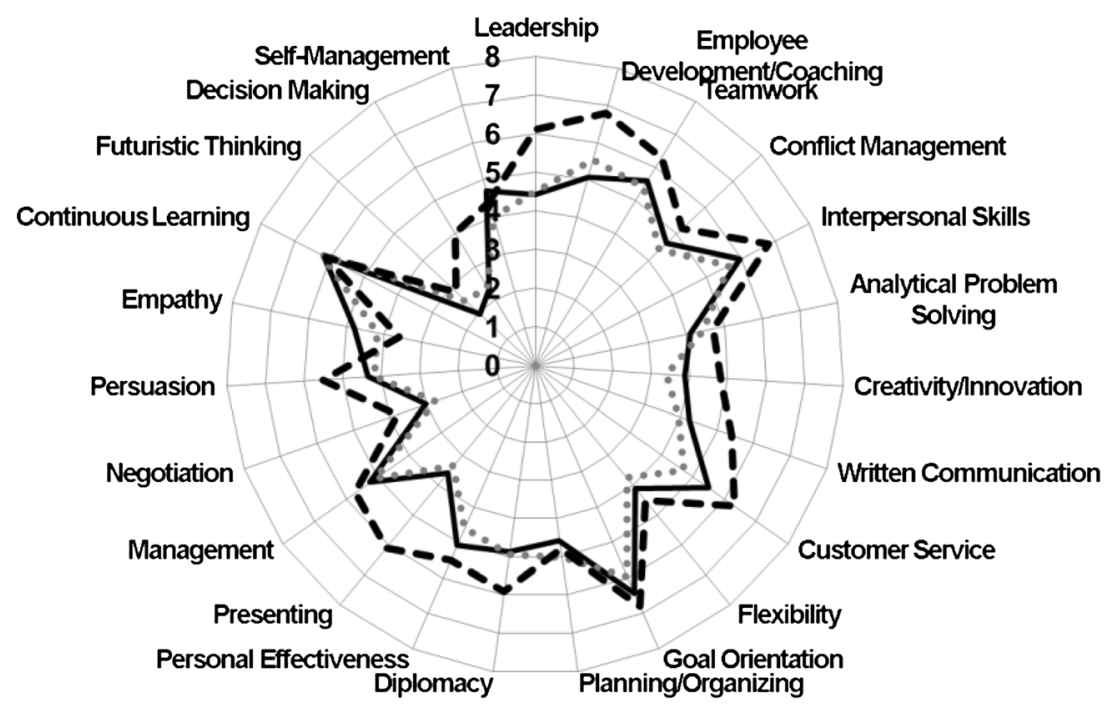

-Pre-Program …Post-Program - -Work Force Mean

\section{Reference}

Pistrui D, Layer JK, Dietrich S (2012) Mapping the behaviors, motives and professional competencies of entrepreneurially minded engineers in theory and practice: an empirical investigation. Proceedings American Society for Engineering Education 2012 Annual Conference, June 10-13, 2012, San Antonio, Texas 